\title{
CORRECTIONS
}

\section{Statement on corrections}

\author{
Editors, Indian Journal of Medical Ethics
}

The comment "Increased incidence of cervical cancer in Sweden: Possible link with HPV vaccination" was published in the Indian Journal of Medical Ethics online on April 30, 2018 (1). The author gave his name and affiliation as Lars Andersson, department of Physiology and Pharmacology, Karolinska Institutet (KI), Sweden.

On May 8, KI informed us that its department of Physiology and Pharmacology did not have any person of this name and requested us to remove the name of the institution. So, the same day a correction was carried out and Kl's name was removed and duly intimated to $\mathrm{KI}$.

Since then, we have investigated and learned the identity of the author. The author has said that he used a pseudonym because he believed the use of his real name would have invited personal repercussions from those opposed to any questioning of vaccines.

This deception of the journal's editors is unacceptable. The author could have asked the editors for confidentiality, giving the reasons. Editors may choose to publish articles without revealing the true name of the author, if it is determined that the circumstances justify it.

However, we considered the matter and decided to keep the article on the site as the issues raised by it are important and discussion on it is in the public interest. The author's true name is withheld at his request.

Note: Corrected on July 22, 2018

1. Andersson L. Increased incidence of cervical cancer in Sweden: Possible link with HPV vaccination. Indian J Med Ethics. Published online on April 30, 2018. DOI: 10.20529/JJME.2018.037. Available from: http://ijme.in/articles/increased-incidence-of-cervical-cancer-in-sweden-possible-link-with-hpvvaccination/?galley=html

Author: ， Indian Journal of Medical Ethics (ijme.editorial@gmail.com)

To cite: Editors, Indian Journal of Medical Ethics. Statement on Corrections. Indian J Med Ethics. 2018 Jul-Sep;3(3) NS:245. DOI: 10.20529/JME.2018.040.

Published online on May 9, 2018.

(c) Indian Journal of Medical Ethics 2018 